\title{
Ethics
}

\section{Ethics, Law, and Pain Management as a Patient Right}

John K. Hall, MD, and Mark V. Boswell, MD, PhD

From: Department of Anesthesiology,

Texas Tech Health Sciences Center, Lubbock, TX.

Dr. Hall is Associate Professor, and Director of Anesthesiology Residency,

Department of Anesthesiology,

Texas Tech Health Sciences Center, Lubbock, TX

Dr. Boswell is Professor and Chairman of the Department of Anesthesiology, and Director of the International Pain

Center, Texas Tech Health Sciences

Center, Lubbock TX.

Address correspondence: John K. Hall, MD

Department of Anesthesiology Texas Tech Health Sciences Center

36014 th Street Mailstop 8182

Lubbock, TX 79424

Disclaimer: There was no external funding in the preparation of this manuscript.

Conflict of interest: None.

Manuscript received: 05/31/2008 Accepted for publication: 11/09/2008

Free full manuscript: www.painphysicianjournal.com
Ethical and legal considerations in pain management typically relate to 2 issues. The first refers to pain management as a human right. The second involves the nature of the patient-physician relationship as it relates to pain management. Although pain physicians often like to think of pain management as a human right, it remains difficult to support this position as a point of law or as a matter of ethics. Medical organizations generally do not define pain management as a specific duty of the physician, apart from the provision of competent medical care. To date, neither law nor ethics creates a duty of care outside of the traditional patient-physician relationship. Absent a universal duty, no universal right exists. Pursuing pain management as a fundamental human right, although laudable, may place the power of the government in the middle of the patient-physician relationship. Despite apparent altruistic motives, attempts to define pain management as a basic human right could have unintended consequences, such as nationalization of medicine to ensure provision of pain management for all patients.

Key words: Ethics, law, patient-physician relationship, human right, pain management

Pain Physician 2009; 12:499-506

"The relief of suffering, it would appear, is considered one of the primary ends of medicine by patients and lay persons, but not by the medical profession." (1)

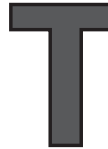

he intersection of law and ethics holds little interest largely due to a lack of conflict. Congruence presents few interesting situations. Divergence produces qualitatively more interest yet fewer answers. When ethics, the personal moral compass, conflicts with law, then physicians must assess not only patient interest but the level of personal and professional risk. Ethical and legal considerations in pain management typically relate to 2 issues. The first is pain management as a right. The second relates to the nature of the patient-physician relationship with specific regard to pain management. 
Ethics and law rarely lead to divergent conclusions. More frequently law or ethics will offer only silence regarding a point of concern in patient care. We examine the issue of law and ethics from the perspective of patient rights for pain management.

\section{Ethical Requirements}

\section{Elements of Ethics}

Ethics provides a general framework for examining the moral life (2). The definition raises the more difficult question of morality. "[M]orality refers to norms about right and wrong human conduct that are so widely shared that they form a stable (although usually incomplete) social consensus" (2). Medical ethics, as regards physicians consists of those physician behaviors not compelled by a regulatory or legislative body.

Early childhood, life, and educational experiences give fundamental calibration to our moral compass. In professional life physician organizations promulgate codes of ethics. Many of these codes refer directly to the American Medical Association (AMA) (3). Pain-related organizations with ethical codes or guidelines include The American Pain Society (APS), The American Society of Anesthesiologists (ASA), The American Society of Interventional Pain Physicians (ASIPP), and The American Board of Pain Medicine (ABPM).

\section{Ethical Codes}

The AMA Principles of Medical Ethics ("AMA Principles") does not specifically address pain management (3). The AMA Principles do require competence (Principle I) and respect for patient rights (Principle IV). These principles compel pain relief, personally or through referral, only as a component of competent, respectful care, not independently. The AMA Principles also require honesty in all professional interactions (Principle II) as well as emphasizing the primacy of the responsibility for the patient (Principle VIII). These last 2 principles assume significance in valid informed consent and require disclosure or resolution of conflicts of interest (3).

The ASA, which includes pain physicians, explicitly incorporates the AMA Principles into the organization's "Guidelines for the Ethical Practice of Anesthesiology" (4). The ASA Guidelines contain additional anesthesia-specific responsibilities. None deal specifically with pain management.

The Ethical Principles of the APS also adopt the AMA Principles. The Ethical Principles for Pain-Related
Clinical Practice "should apply to all clinical disciplines engaged in pain therapy" but does not specifically address pain management (5).

In contrast, the mission statement of ABPM "is to serve the public by improving the quality of Pain Medicine" (6). Associated goals and objectives focus on the duties of the organization to assure the quality of diplomates. No explicit reference is made to pain management for individual patients.

ASIPP has 3 relevant documents. The ASIPP bylaws, in part, delineate the society's purpose as:

a. To promote the development and practice of safe, high quality, cost effective interventional pain management techniques for the diagnosis and treatment of pain related disorders, and to ensure patient access to these interventions.

b. To preserve and increase reimbursement for interventional pain management techniques.

...

j. To provide the best possible interventional pain management (7).

The ASIPP mission statement further indicates that its mission is "to promote the development and practice of safe, high quality, cost-effective interventional pain management techniques for the diagnosis and treatment of pain and related disorders, and to ensure patient access to these interventions" (8). Patient access to interventional pain management has required lobbying efforts to maintain CMS reimbursement for pain procedures.

The World Medical Association (WMA) offers The International Code of Medical Ethics ("WMA Code") (9) and The Declaration on the Rights of the Patient ("WMA Declaration") (10). The WMA Code, like the AMA Principles, does not require specific therapy, including pain management, beyond acting "in the patient's best interest" and referring to another physician when "treatment is beyond the physician's capacity." In contrast to most of the other codes the WMA Declaration defines an "entitlement" of patients to "relief of his/her suffering according to the current state of knowledge" (10). However, the bulk of relevant medical ethics authority offers little support for specific pain management beyond that encompassed by good medical care.

\section{Legal Requirements}

The law related to pain management provides a larger volume but only slightly greater clarity of direction than published ethical principles. In general 
laws fall into one of 3 categories: 1) A law compels a particular behavior under certain circumstances. 2) A law may prohibit a particular behavior under certain circumstances. 3) A law may leave discretion to the physician or may provide only ambiguous direction. The first 2 types of regulations do not simply represent opposite heads of the same coin, except when there exists only a single alternative to clinical care. In fact, the regulations relate predominantly to payment and reporting requirements rather than actual clinical care. State governments and agencies accomplish this function through direct control by promulgating statutes and agency regulations as well as limitations on funding. The last category tends to cause more difficulty because of the absence of bright line clarity for the physician. In any of these cases the first question that must be asked is "What does pain management mean?" The second question is "Does the law require me to manage pain?" The third and final question is "Are there any limitations?"

The first question is quickly resolved. For our purposes, we consider pain management to consist of specific therapy for an underlying pathophysiology. This causes little difficulty for most physicians because pain is a common symptom prompting the patient to seek medical attention. Moreover, the doctor usually seeks an underlying etiology of the pain. We also distinguish pain management from pain relief. Safe pain relief may not always be achievable or consistent with good medical care outside the bounds of the "double effect."

Pain without clear etiology presents more difficulty because it reduces therapy to symptom palliation. Risk management, in the form of minimizing patient complications or reduction of physician liability, may predominate. In these cases, therapeutic endpoints become indistinct. The ability to estimate risks and benefits declines as patient credibility and subjectivity replace objective data. Physicians, other than pain specialists, often become uncomfortable treating pain without a clear diagnosis.

\section{Federal Law}

A wide variety of federal and state agencies have the authority under the appropriate administrative procedures act to regulate health care in some manner (11). The best known agency is probably the Centers for Medicare and Medicaid Services (CMS), a division of the Department of Health and Human Services (HHS). CMS administers Medicare (11). CMS permits payment for a wide variety of pain services. Yet even CMS does not compel therapy. In fact, its role as payer provides a restriction to access. Demand by CMS or any payer for evidence of therapeutic efficacy forces physicians to make evidence-based choices and may deprive patients of potentially beneficial therapies. Yet even agencies such as CMS do not require pain management except in a few circumstances.

The federal government has a long history of prosecuting under the False Claims Act those physicians and health care entities that fail to provide services CMS views as included in the services paid for by CMS. Anytime CMS expects pain management, failure to provide the expected therapy may constitute fraud. Therefore, in cases such as hospice care that traditionally include pain management as a component of palliative or end-of-life care, failure to provide sufficiently comprehensive care precludes legitimate compensation.

The Food and Drug Administration (FDA) may limit care through the approval process of drugs and medical devices. CMS may control access by limiting payment. However, The Drug Enforcement Agency (DEA) indirectly limits pain therapy through registration of physicians and monitoring of prescribing practices. The DEA was created by executive order and is charged primarly with enforcing the Controlled Substance Act $(12,13)$. The DEA mission statement starts with "The mission of the Drug Enforcement Administration (DEA) is to enforce the controlled substances laws and regulations of the United States...." Nothing in the DEA mission statement relates to assuring adequate pain management or access to controlled drugs for individual patients. Quite the contrary, the DEA exposes physicians to substantial criminal and civil liability. In short, the DEA exists to prosecute those who illegally distribute controlled substances.

In 2007, the United States prosecuted Dr. William Elliot Hurwitz on 45 counts of drug trafficking. The jury convicted him of 16 counts and acquitted him of 17. U.S. District Judge Leonie M. Brinkema dismissed the remaining 12 counts. His conviction and sentence of 4.5 years followed months of testimony (14). In response to Hurwitz, "DEA Administrator Karen P. Tandy said, 'DEA remains committed to striking a balance between promoting pain relief for patients in need and preventing abuse of pain medications. There has been no change in our enforcement strategy, and doctors should remain confident in their ability to treat patients in pain. On the other hand, for doctors like Dr. 
Hurwitz, DEA will not shy away from its enforcement policies.'" (15).

Few physicians understand the intricacies of Hurwitz's conviction. However, lack of knowledge does not prevent physicians from using Hurwitz as a reason to avoid narcotic prescribing. Tandy's assertions offer little assurance in a situation with such high stakes, especially while the DEA indicates approximately 120 active criminal prosecutions of physicians (16).

In spite of Hurwitz's high profile there appears to be very little risk from appropriate prescribing of controlled drugs by state agencies $(17,18)$. Even if eventually acquitted, investigation and indictment may cause irreversible harm to one's reputation and financial hardship without the possibility of recovery.

Returning to the previous questions we find that no Federal law requires the treatment of pain. The only exception might be circumstances under which pain management is considered an integral component of the services rendered. Regarding limitations, insight and caution must guide the practice of pain management to avoid damage to reputation and financial devastation from unnecessary scrutiny by Federal agencies.

\section{State Law}

Many states have some form of "pain control act "(19). Generally such acts protect physicians caring for patients with pain as long as the patient meets enumerated criteria and the physician acts in compliance with the act. The model act requires compliance with the "Comprehensive Drug Abuse Prevention and Control Act of 1970 ( 21 U.S.C. §§ 801 et seq. [or applicable state statute])"(19). Such statutes offers little or no protection to physicians such as Hurwitz, charged by the federal government.

Every state in the United States has an agency charged with licensing physicians and regulating the quality of medical care for the citizens of the state. Each of these agencies has, as an integral part of its mission, the protection of the citizens of the state. With variable stringency the state agency assesses and enforces standards of good medical practice. As an example, The California Medical Board, which is not significantly different from other states, has the following mission statement:

The mission of the Medical Board is to protect healthcare consumers through the proper licensing and regulation of physicians and surgeons and certain allied healthcare professions and through the vigorous, objective enforcement of the Medical Practice Act, and, to promote access to quality medical care through the Board's licensing and regulatory functions. (20).

The California Board's mission statement neither specifically addresses nor compels pain management, other than to the extent that failure to provide pain management deviates substantially from quality care. We chose California so that we may examine it more closely below.

\section{Common Law}

The common law presents the most compelling source of legal obligation for physicians. The doctorpatient relationship finds its origin on contract law principles (21). Traditionally, the relationship requires physician and patient consent. Typically, a patient seeks a physician's care and the physician generally accepts the patient. Neither the patient nor the physician expressly defines the contours of the agreement. Although informal, each party to the contract incurs certain obligations. This informal agreement suffices. Consent need not be expressed (22). The patient subsequently expects the physician to act according to known legal and ethical principles - possibly including the AMA Principles. Absent some explicit delineation to the contrary the patient's expectations seem intrinsically reasonable.

Maintenance of the ongoing physician-patient relationship rests partly on fulfillment of contractual duties. Yet the principles of agency law compose the bulk of the legal basis for the ongoing relationship. The physician-patient relationship should be fiduciary in nature. The physician/fiduciary should act strictly on behalf of the patient/principle. The law generally requires the highest standards of care from fiduciary relationships. Fiduciary relationships require that the physician not profit from the relationship beyond the compensation defined for the services rendered. A fiduciary must disclose conflicts of interest. A fiduciary should receive expressed consent for any activity derived from the relationship that profits the fiduciary or compromises the patient's interest. Agency principles demand physician behavior similar to but less rigorous than the ethical codes discussed above.

Agency principles may have more usefulness because they create clearer rules. The AMA Principles require that the physician "regard responsibility to 
the patient as paramount" but specifies "while caring for the patient" (Principle VIII) (emphasis added) (3). Strictly interpreted, the AMA Principles do not require disclosure of physician self-interests that are neither adverse nor detrimental to the patient's interest. In essence, any incidental secondary gain derived from the physician-patient relationship is permissible.

AMA Principle II presents the only limitation to this interpretation. AMA Principle II requires professionalism and honesty in all professional interactions. This requires, at best, that a physician disclose nondetrimental secondary gain. The patient need not consent to the physician's incidental gain. Further, the AMA principles do not prohibit subjugation of the patient's interests to those of the physician's after the conclusion of the physician-patient relationship.

If the physician acts as a fiduciary, the physician must receive consent to derive additional benefit from the physician-patient relationship beyond the agreed compensation. Using the attorney-client relationship as a model, a substantial portion of the fiduciary duty should survive termination of the relationship. Not all physicians consider themselves morally or ethically superior to attorneys but few probably consider themselves inferior.

A fiduciary relationship imposes a higher and arguably clearer standard. In essence if the physician derives anything of value, beyond common knowledge, as a result of the relationship, disclosure to the patient is required. Some benefits are within the common knowledge. For example, the benefit to the physician of additional referrals as a result of good patient care need not be disclosed. Further, patient consent is likely required.

The contractual nature of the physician-patient relationship imposes powerful duties on the physician. Within the therapeutic dyad of the patient-physician relationship, the duties are legally enforceable. The courts generally enforce the duties as negligence, most commonly malpractice (23). Legal action may also arise as negligent or intentional infliction of emotional distress if physician conduct is especially egregious $(24,25)$. These cases foretold the first California suit against a physician for failure to manage pain.

In February of 1998, the Eden Medical Center in Castro Valley, California, admitted William Bergman under the care of Dr. Wing Chin. Bergman, an 85-yearold smoker, complained of severe pain. Details of his hospitalization and care remain disputed. His history and subsequent studies raised a strong suspicion of lung cancer. Bergman declined additional studies and was discharged. He died within one week of discharge to hospice care. The malpractice suit against Chin was dismissed. The hospital settled with Bergman's family. The family successfully sued Chin under California's Elder Abuse and Dependent Adult Civil Protection Act $(25,26)$.

The decision against Chin seems modest compared to a prior case in which the estate was awarded 15 million dollars $(\$ 15,000,000)$ as a result of a nurses decision to "under-medicate" a terminally ill nursing home patient (26). Bergman's family was initially awarded 1.5 million dollars $(\$ 1,500,000)$ but the verdict was eventually reduced to $\$ 250,000$ through the application of California's malpractice cap. Bergman has enormous potential for persuasive precedential value. Bergman in combination with James sends a clear message that civil courts can determine whether a provider meets a duty of care for an identified patient $(24,25)$.

State law, therefore, provides different answers from Federal law regarding requirements for pain management and limitations. State licensing agencies may compel therapy within particular standards. The standard is generally low - only simple competence consistent with the physician's knowledge and training need be demonstrated. State agencies have little ability to require a physician to treat a particular patient so that requirements for competence extend only to existing therapeutic relationships. (See discussion regarding Thirteenth Amendment below.)

In contrast to state agencies, contractual relationships recognized under state laws exert powerful control over the patient-physician relationship. Modern contractual relationships extend beyond the therapeutic dyad. Physicians may incur contractual obligations to treat entire groups of patients through relationships with third-party payers. Physicians typically maintain the right to refuse patients for cause but must treat patients within their scope of practice. In these cases, physicians must carefully define limits on their practices to avoid liability in tort or contract. In Bergman the court found Chin liable due to a California statute. Yet Chin's liability arose due to the fact that he had a patient-physician relationship with Bergman. The relationship was the crucial component of the decision. Chin would have no liability to random, unassigned patients. Thus the common law 
and administrative authorities of licensing and other agencies impose a duty upon a physician in an established, contractual or therapeutic relationship. Such duties may establish a right to pain management in a particular patient.

Finally, limitations regarding pain management imposed by states become apparent. State Pain Control Acts offer some protection for physicians engaging in legitimate pain management practices. However, breeches of good practice of the magnitude committed by Hurwitz likely will continue to attract Federal prosecutorial interest.

Clearly, neither ethics nor law compels pain management other than as an integral component of good patient care. So, is pain management a right?

Pain is a symptom. No objective measure currently exists. Despite intense study, pain remains a complex manifestation of neurologic, psychologic, and sociologic responses to a perceived painful stimulus. No other symptom is so easily falsified with such reliable responses from health care and lay communities. In fact, other symptoms such as dizziness and tinnitus are rarely discussed absent an etiology. Itch is an unusual symptom in that, like pain, it can appear anywhere on the body from a wide variety of etiologies.

Consider a quote from a recent review article: "[T]he unreasonable failure to treat pain is poor medicine, unethical practice, and is an abrogation of a fundamental human right" (27). The quote is no less accurate if the symptom "pain" is replaced with "itch." In fact itch has long been recognized as a cause of human suffering (28). Itch has been associated with suicide since the early twentieth century (28). From this perspective, itch appears indistinguishable from pain (and may involve pain mechanisms, such as activation of $C$ fibers). Perhaps if itch had the same political emphasis as pain, with equal opportunity for compensable interventional and invasive therapy, it would be a more popular symptom. Would anyone consider itch treatment per se a basic human right? It seems unlikely.

Any additional doubt regarding pain management as a basic human right may be dispelled by examining the nature of "rights." The usual argument starts with a description of physician duties and makes the transition from general duty of good care to the specific duty of pain relief (notably omitting other symptoms such as itch) $(27,29)$.

Human rights fall into 2 classes. In the United States, basic human rights are those defined in the
Constitution or protected by statute. The Constitution or statute prevents the government from abridging these rights without substantial or compelling reason. The best known example remains Roe v. Wade. The United States Supreme Court (Court) did not give Roe the right to an abortion. The Court instead acknowledged Roe's right to choose as a personal liberty under the Bill of Rights and Due Process Clause of the Fourteenth Amendment. The Court then defined the circumstances under which the state may violate Roe's right (30). With the exception of the prohibition against slavery embodied in the Thirteenth Amendment to the Constitution, human rights are protected against infringement by the state.

If pain management were a basic human right, the government would have few ways to enforce the right. No laws yet exist prohibiting pain management. But suppose the government "required" pain management. The requirement would have the effect of an affirmative injunction. Against whom should the injunction issue? Even if the responsible party were unambiguously identified, the U.S. has a long history of non-enforcement of affirmative injunctions; the usual reason being that such injunctions tread dangerously close to violating the Thirteenth Amendment.

One of the few mechanisms to secure a basic human right is a nationalized service. In the United States basic freedoms are assured by police, members of the executive branch, and nationally by the military, also the executive branch. The executive branch is checked and balanced by the legislative and judicial branches. If basic human rights become affirmative rights, then there is likely no alternative to a nationalized health care service (more specifically a nationalized pain care service). Members of the service would be essentially civil servants treating any or all pain patients for whatever salary compensation the controlling agency deems appropriate. We suspect that this would reduce pain to a level of importance commensurate with other symptoms.

A national cadre of pain management physicians offers the additional benefit of control over technology and techniques to assure compliance with evidence-based standards. Such a service prevents the all too frequent "orphaning" of chronically ill pain patients due to lack of funding. The associated loss of professional autonomy and the decrement in physician income would seem to represent a small price to pay in defense of a basic human right. 
The government may prohibit physicians from practicing substandard medicine (or even require a practice of medicine within an accepted standard of care), but in general, the government may not require specific therapy under particular circumstances or for a specified patient. If the constitutional issues are mitigated, the problem of other symptoms persists. Should sufferers of vertigo, tinnitus, or itch be treated as less than full citizens and denied similar Constitutional or statutory protections? Under this analysis the argument that pain management is a basic human right seems less defensible.

The second class of human rights comprises individual rights arising from a special relationship. These encompass fiduciary responsibilities, duties of due care, or negotiated rights arising from contract. The patient-physician relationship is associated with this class of rights. Once created, the therapeutic dyad offers the patient protection. The protection arises through the physician's fiduciary responsibilities. Additional protection derives from the requirements of minimal standards of care and compliance with ethical principles imposed by licensing and regulatory agencies. Finally, patients find protection in statutorily imposed duties, such as the elder abuse statute in Bergman.

As seen in the cases of James and Bergman these individual rights wield enormous power to enforce care consistent with reasonable standards. These rights also permit patients to present their cases be- fore a jury when physicians breech their duties. To date, nothing creates a duty of care outside of the traditional patient-physician relationship. Absent a universal duty no universal right exists. As noted, designating any portion of health care as a basic human right carries with it the possibility of nationalization of the current state-sponsored monopolies we currently enjoy.

\section{SUMMARY}

Ethical and legal considerations in pain management typically relate to 2 issues. The first is pain management as a right. The second is the nature of the patient-physician relationship as it relates to pain management. Although pain physicians often like to think of pain management as a human right, law and ethics do not provide clear support of this position. Medical organizations generally do not define pain management as a specific duty of the physician, apart from the provision of competent medical care. To date, neither law nor ethics creates a duty of care outside of the traditional patient-physician relationship, and absent a universal duty, no universal right exists. Pursuing pain management as a fundamental human right may further entrench the government in the middle of the patient-physician relationship. Despite altruistic motives, attempts to define pain management as a basic human right could have unintended consequences, such as nationalization of medicine to ensure provision of that right for all patients.

\section{References}

1 Cassell EJ. The Nature of Suffering and the Goals of Medicine. NEJM 1982; 306: 639-645.

2. Beauchamp TL and Childress JF. Principles of Bioethics. $5^{\text {th }}$ edition. Oxford University Press, Oxford, 2001, pps 1-7.

3. American Medical Association Principles of Medical Ethics. www.ama-assn. org/ama/pub/category/2512.html. Accessed 5/20/2008.

4. Guidelines for the Ethical Practice of Anesthesiology. www.asahq. org/publicationsAndServices / standards/10.pdf Accessed 5/23/2008.

5. Ethical Principles for Pain-Related
Clinical Practice. www.ampainsoc.org/ about/ethics.htm.

Accessed 5/23/2008.

6. The ABPM Mission Statement. www. abpm.org/about/index.html. Accessed $5 / 23 / 2008$

7. Bylaws of the American Society of Interventional Pain Physicians, Inc. www.asipp.org/documents/ ASIPPBylawsJuly2007_001.pdf. Accessed 5/23/2008.

8. ASIPP Mission Statement. www.asipp. org/about_us.html.

Accessed 5/23/2008.

9. World Medical Association International Code of Medical Ethics. www.wma.net/ e/policy/c8.htm. Accessed 5/23/2008.
10. World Medical Association Declaration on the Rights of the Patient. www. wma.net/e/policy/l4.htm. Accessed 5/23/2008.

11. Administrative practice; general provisions Administrative Procedure Act 5 USC $\S 500$ et seq.

12. Drug Enforcement Adminstration. Executive order number 11727 , July 6 , 1973; 38 F.R. 18357.

13. Controlled Substance Act: 21 USC $\S 801$ et seq.

14. www.washingtonpost.com/ wp-dyn/content/article/2007/04/27/ AR2007042702204.html. Accessed 5/23/2008

15. Virginia Pain Doctor Sentenced to 25 
Years. www.usdoj.gov/dea/pubs/ pressrel/pro41405.html.

Accessed 5/23/2008

16. Cases against doctors.

www.deadiversion.usdoj.gov/crim admin_actions/index.html

17. Ziegler SJ, Lovrich NP. Pain Relief, Prescription Drugs and Prosecution: A Four-State Survery of Chief Prosecutors, Journal of Law, Medicine and Ethics, 2003; 31:75-1000.

18. Alpers A. Criminal Act or Palliative Care? Prosecutions Involving Care of the Dying, Journal of Law, Medicine and Ethics 1998; 26:308-331.

17. www.painandthelaw.org/statutes/ model_act.php
18. www.medbd.ca.gov/

19. Childs v Weis, 440 S.W. 2d 104 (Ct. Cv.App.Tx. 1969)

20. St. John v. Pope, 901 S.W.2d 420 (Tx 1995)

21. Bardessono v. Michaels, 478 P.2d 480 (CA 1970)

22. Oswald v. Legrand, 453 N.W.2d 634 (lowa 1990) 22

23. Wargelin v. Sisters of Mercy Health Corporation, 385 N.W.2d 732 (Mich. Ct. App. 1986)

24. CA Welf. \& Inst. Code $\$ 15610.07$ Bergman v Wing Chin and Eden Medical Center, No. H205732-1 (Cal App Dept Super Ct 1999)

25. Estate of Henry James v. Hillhaven Corp.,
No. 89 CVS 64 (N.C. Super. Ct. Jan. 15, 1991)

26. Brennan F, Carr DB, Cousins M. Pain Management: A Fundamental Right. Anesth Analg 2007; 105:205-221.

27. The Diagnosis of Diseases of Women: $A$ Treatise for Students and Practitioners, Findley P. Lea Brothers and Co., Philadelphia, 1903.

28. Yosipovitch G, Greaves MW, Fleischer AB, McGlone $F$ (eds). In: Itch: Basic Mechanisms and Therapy. Marcel Dekker, Inc, 2004.

29. Johnson, SH., Legal and Ethical Perspectives on Pain Management. Anesth Analg 2007; 105: 5-7.

30. Roe v. Wade, 410 U.S. 113 (1973) 